\title{
Evaluation of serum protein-based arrival formula and serum protein supplement (Gammulin) on growth, morbidity, and mortality of stressed (transport and cold) male dairy calves
}

\author{
A. Pineda, ${ }^{*}$ M. A. Ballou, $†$ J. M. Campbell, $\ddagger$ F. C. Cardoso, ${ }^{*}$ and J. K. Drackley ${ }^{* 1}$ \\ *Department of Animal Sciences, University of Illinois, Urbana 61801 \\ †Department of Animal and Food Sciences, Texas Tech University, Lubbock 79409 \\ ¥APC Inc., Ankeny, IA 50021
}

\begin{abstract}
Previous studies with calves and other species have provided evidence that blood serum-derived proteins and fructooligosaccharides (FOS) may benefit intestinal health. We assessed the effects of supplementing products containing serum proteins as a component of arrival fluid support or serum proteins plus FOS (in addition to additional solids, minerals, and vitamins) in an early life dietary supplement on performance, morbidity, and mortality of stressed (transport, cold) male calves. Male Holstein calves $(\mathrm{n}=93)<1$ wk old were stratified by arrival body weight (BW) and plasma protein concentration, and then randomly assigned to 1 of 4 treatment groups in a $2 \times 2$ factorial arrangement of one-time administration of fluid support [either control electrolyte solution (E) or the serum protein-containing arrival formula $(\mathrm{AF})]$ and $14 \mathrm{~d}$ of either no supplementation (NG) or supplementation with Gammulin (G; APC Inc., Ankeny, IA), which contains serum proteins and FOS in addition to other solids, minerals, and vitamins. Upon arrival at the research facility, calves were orally administered either AF or E. At the next feeding, half of the calves from each fluid support treatment received either milk replacer (20\% crude protein, $20 \%$ fat) or the same milk replacer supplemented with $\mathrm{G}$ (50 g/d during the first $14 \mathrm{~d}$ ). Starter and water were freely available. Feed offered and refused was recorded daily. Calf health was assessed by daily assignment of fecal and respiratory scores. Stature measures and BW were determined weekly. Blood samples were obtained at d 0 (before treatments), 2, 7, 14, and 28. Calves were weaned at d 42 and remained in the experiment until d 56. After 2 wk of treatments, calves previously fed AF had greater body length ( 66.6 vs. $66.0 \mathrm{~cm})$, intakes of dry matter (38.7 vs. $23.5 \mathrm{~g} / \mathrm{d}$ ) and crude protein
\end{abstract}

Received March 29, 2016.

Accepted July 28, 2016.

${ }^{1}$ Corresponding author: drackley@illinois.edu
(9.2 vs. $5.6 \mathrm{~g} / \mathrm{d})$ from starter, and cortisol concentration in blood (17.0 vs. $13.9 \mathrm{ng} / \mathrm{mL}$ ) than calves fed E. Supplementation with G resulted in greater BW gain during the first $2 \mathrm{wk}$, increased intakes of dry matter and $\mathrm{CP}$, and decreased respiratory scores. For the 8-wk experiment, G supplementation resulted in lower mean fecal score (1.6 vs. 1.8) and fewer antibiotic treatments per calf (1.5 vs. 2.5$)$ than NG. Survival was greater in $\mathrm{G}$ than in NG calves (98 vs. $84 \%$ ). Despite the marked reduction in morbidity and mortality, blood indicators of acute-phase response, urea $\mathrm{N}$, and total protein were not affected by AF or G in transported cold-stressed male calves.

Key words: calf, serum protein, acute phase response

\section{INTRODUCTION}

The most challenging period for young calves is from birth through weaning; during this time calves experience remarkable physiological, metabolic, and environmental changes (Davis and Drackley, 1998). Despite advances in calf nutrition and health, morbidity and mortality are greater during this time than at any other point of the animal's life (Quigley et al., 2005; NAHMS, 2010). The main causes of mortality during the preweaned period are diarrhea and respiratory problems, with most of the deaths occurring during the first 2 to 3 wk of life (NAHMS, 2010). For the dairy enterprise, decreasing morbidity and mortality is important because of the economic losses associated with treating illnesses, decreased calf performance, and death. Factors associated with morbidity and poor performance during the preweaned period are inadequate feeding, poor management, and the presence of stressors such as cold weather and transport (Wells et al., 1996; Svensson et al., 2006b; Vasseur et al., 2010).

Success in calf rearing is a function of excellent nutrition and management practices that start as soon as the calf is born. Adequate colostrum intake and provision of a dry, comfortable, and clean environment to minimize exposure to pathogens are the first steps 
to provide better adaptation of the newborn calf to its new environment (Quigley et al., 1995; Godden, 2008). Colostrum-deprived calves exposed to unfavorable conditions (e.g., high pathogen loads, environmental stressors) after birth exhibit greater risk for morbidity and mortality (Quigley et al., 2005; Godden, 2008; Gulliksen et al., 2009). Subsequent nutrition is crucially important to provide all nutrients for proper growth and health; however, adequate nutrition is not enough to ensure proper survival, growth, and health in circumstances where the young calf is immunologically disadvantaged, facing unfavorable environmental conditions, or subjected to other stressors. Transport (Johnston and Buckland, 1976; Odore et al., 2004) and cold weather represent stressors for the young calf, affecting its immune system (Odore et al., 2004; Fike and Spire, 2006) and increasing the susceptibility to enteric and respiratory problems (Fike and Spire, 2006; Svensson et al., 2006a), which are the principal causes of high morbidity and mortality during the preweaned period (NAHMS, 2010).

Dietary supplements or additives that would improve nutrition and diminish the negative effects of poor management and unfavorable conditions would be useful for calf managers. Previous research with calves (Arthington et al., 2000b; Quigley et al., 2002) suggested that serum protein products improve health and decrease morbidity and mortality (Quigley and Wolfe, 2003) while maintaining or increasing growth. In addition, studies in humans and other species have shown that fructooligosaccharides (FOS) stimulate growth of beneficial bacteria in the gastrointestinal tract, inhibit colonization by pathogens, and improve mineral absorption (Howard et al., 1995; Sabater-Molina et al., 2009; Grand et al., 2013). Based on these data, our prediction was that products containing serum proteins or serum proteins plus FOS, in addition to milk products (dried whey and dried whey protein concentrate), minerals, and vitamins, would improve performance, morbidity, and mortality of dairy calves subjected to the stressors of winter cold weather and transport, especially during their first 2 to $3 \mathrm{wk}$ of life. Therefore, the aim of the present study was to evaluate the effects of an arrival fluid support product containing serum proteins or an early life dietary supplement containing serum proteins and FOS among other ingredients on performance, morbidity, and mortality of stressed male calves.

\section{MATERIALS AND METHODS}

\section{Calf Management and Experimental Design}

All procedures were approved by the University of Illinois Institutional Animal Care and Use Commit- tee. Ninety-three male Holstein calves $<1$ wk old were purchased from dairy farms in western New York State by a buyer in 3 blocks of 30 to 32 calves each and transported to the University of Illinois Nutrition Field Laboratory. Calves were transported in a livestock trailer and subjected to a $\sim 14$-h trip. The first group was acquired in February 2009 (32 calves), the second group in November 2009 (31 calves), and the third in January 2010 (30 calves).

Each group of calves was examined by the veterinary staff upon arrival. The evaluation included heart and lung auscultation, hydration status, alertness, mobility, navel status, and body temperature. After receiving an ear tag in the left ear calves were subjected to a standard arrival and postarrival processing scheme. A blood sample was obtained by jugular venipuncture and plasma protein was determined by refractometry. Calf BW was measured.

Calves were stratified by arrival BW and plasma protein concentration, blocked, and assigned randomly within blocks to 1 of 4 treatments. Treatments were in a $2 \times 2$ factorial arrangement of type of arrival fluid support (AFS) and early-life dietary supplementation (SUP). The AFS factor comprised one-time administrations of either control electrolyte solution $(\mathbf{E})$ or arrival formula (AF). The SUP factor consisted of either no supplement (NG) or $14 \mathrm{~d}$ of supplementation with a commercial product (Gammulin; APC Inc., Ankeny, IA) containing serum proteins and FOS $(\mathbf{G})$. The resulting individual treatments, therefore, were EN ( $\mathrm{n}=$ $25), \operatorname{AFN}(\mathrm{n}=24), \mathbf{E G}(\mathrm{n}=22)$, and AFG $(\mathrm{n}=22)$.

Calves were housed in individual hutches (Calf-tel, Hampel Corp., Germanton, WI) bedded deeply with straw over crushed rock covered with landscape cloth. Straw was added to each hutch daily as needed. All calves were castrated by the veterinary staff via surgical removal of the testicles using local anesthesia $1 \mathrm{wk}$ after arrival. Calves remained in hutches from arrival until the end of the experiment at d 56 when they were sold.

\section{Feeds and Feeding Program}

The AF (APC Inc.) fluid support supplement was administrated via nipple feeder or esophageal feeder upon arrival, and was prepared by mixing for each calf $250 \mathrm{~g}$ of $\mathrm{AF}$ in $2 \mathrm{~L}$ of warm $\left(45^{\circ} \mathrm{C}\right)$ water. The ingredient composition of AF included spray-dried bovine serum in addition to milk products (dried whey and dried whey protein concentrate), minerals, electrolytes, and vitamins. Administration of AF was compared with administration of a commercial electrolyte solution (Land O'Lakes electrolyte system; Land O'Lakes Animal Milk Products Co., Arden Hills, MN), which was prepared 
by mixing $77 \mathrm{~g}$ in $2 \mathrm{~L}$ of warm $\left(45^{\circ} \mathrm{C}\right)$ water. Therefore, each calf received one 2 - $\mathrm{L}$ feeding of either $\mathrm{AF}(\mathrm{n}=46)$ or $\mathrm{E}(\mathrm{n}=47)$.

At the next feeding, all calves received a nonmedicated milk replacer (Sav-A-Caf; Milk Products LLC, Chilton, WI), containing all milk proteins, $20 \% \mathrm{CP}$, and $20 \%$ fat. The milk replacer was either not supplemented (NG) or supplemented with $\mathrm{G}$ by adding 25 $\mathrm{g}$ at each feeding $(50 \mathrm{~g} / \mathrm{d})$ to the reconstituted milk replacer during the first $14 \mathrm{~d}$ after arrival only. Gammulin nutritional supplement contained bovine serum, FOS (inulin), dried whey, maltodextrin, minerals, and vitamins. Milk replacers were reconstituted to $12.5 \%$ solids (not including G supplementation) and were fed at a rate of $10 \%$ of arrival $\mathrm{BW}$ in 2 feedings daily. Beginning on d 3 after arrival, milk replacers were fed at a rate of $12 \%$ of arrival $\mathrm{BW}$ for 2 wk, followed by $10 \%$ of arrival BW during wk 3 to 5 . During wk 6 , the afternoon milk replacer feeding was eliminated, and calves were weaned at d 42 after arrival. Commercial texturized starter (20\% MomentaCalf Starter - RUM; Vita Plus Corporation, Madison, WI) containing 20\% $\mathrm{CP}$ was provided daily to all calves for ad libitum intake from d 4 until 56. Calves were fed at 0530 and $1630 \mathrm{~h}$ each day; milk replacer, starter, and water intakes were recorded daily. Clean, fresh water was provided twice daily, after the morning and evening feedings.

\section{Data Collection}

Calf health status was monitored throughout the day and assessed by daily assignment of fecal and respiratory scores, as well as recording all medical treatments and elevated body temperatures. Fecal scores were recorded using a 1 to 4 scale with the following guidelines: $1=$ firm, well formed (not hard); 2 = soft, pudding-like; $3=$ runny, pancake batter; and $4=$ liquid, splatters. Respiratory scores on a 1 to 5 scale were recorded using the following guidelines: $1=$ normal; $2=$ runny nose; 3 = heavy breathing; $4=$ cough, moist; and $5=$ cough, dry. Body temperatures were recorded daily until d 7 , and at any time when a calf appeared depressed or was off feed.

Calves were measured for BW, withers height, body length, heart girth, hip height, and hip width at arrival and after the morning feeding on the same day each week through wk 8. Individual intakes of milk replacer, starter, and water were measured and recorded daily. For each replicate of calves, milk replacer and starter grain were sampled weekly from wk 1 to 8 , whereas G was sampled during the supplementation period (wk 1 and 2). The AF was only offered and sampled on the arrival day for each replicate of calves. All samples were stored at $-20^{\circ} \mathrm{C}$ and then composited by period and replicate. Composited samples were sent to a commercial laboratory (Dairy One Corporative Inc., Ithaca, NY), where they were analyzed for concentrations of DM, CP, fat, and minerals by wet chemistry methods as described (http://dairyone.com/general-resources/ publications/).

Water intake was determined as free water, water in reconstituted milk replacer, water in feed, and total water intake. Water freely available after feedings was considered as free water. Water in milk replacer was the water used to reconstitute the milk replacer. Water in feed was the water contained in the as-fed starter and milk replacer powder. Total water was the sum of all sources of water.

Samples of blood were obtained at arrival (d 0 ) before the initial feeding and on d 2, 7, 14, and 28 . Blood samples were collected via jugular venipuncture with 20-gauge $\times 2.5 \mathrm{~cm}$ needles (Becton Dickinson and Company, Franklin Lakes, NJ) into 10-mL evacuated tubes for serum (Becton Dickinson and Company) containing clot activator. Samples were allowed to clot at room temperature for at least $30 \mathrm{~min}$ and then placed on ice. All tubes were centrifuged within $2 \mathrm{~h}$ of collection at $4^{\circ} \mathrm{C}$ for $15 \mathrm{~min}$ at $959 \times \mathrm{g}$. After centrifugation, the serum was removed, placed into $5-\mathrm{mL}$ tubes, and stored at $-20^{\circ} \mathrm{C}$ until analysis.

Serum from d 0, 2, 7, and 14 was analyzed for concentrations of $\operatorname{IgG}$ (d 0 only) and acid-soluble protein (ASP), haptoglobin, cortisol, Zn, and albumin to determine evidence of stress and inflammatory responses (Ballou et al., 2011). Serum from d 28 was analyzed for concentrations of urea $\mathrm{N}$ and total protein. Concentrations of albumin, urea $\mathrm{N}$, and total protein were determined at the University of Illinois, College of Veterinary Medicine Clinical Pathology Laboratory using commercially available kits (Olympus America Inc., Center Valley, PA). Concentration of IgG was determined by radial immunodiffusion (RID kit, VRMD Inc., Pullman, WA) by APC Inc. Acid-soluble protein, haptoglobin, cortisol, and $\mathrm{Zn}$ were analyzed at Texas Tech University. Haptoglobin and Zn were determined as described by Makimura and Suzuki (1982) and Ballou et al. (2011), respectively. Cortisol was quantified using an enzyme immunoassay kit (Arbor Assays, Ann Arbor, MI) as described by the manufacturer (http:// www.arborassays.com/documentation/inserts/K003-H. pdf). Acid-soluble protein was determined as follows. Serum samples $(50 \mu \mathrm{L})$ were incubated with $1 \mathrm{~mL}$ of perchloric acid solution (66 mL of $0.6 \mathrm{M}$ perchloric acid diluted in $1 \mathrm{~L}$ of distilled water) for $20 \mathrm{~min}$ at room temperature. Samples were then centrifuged $(1,380 \times$ $g$, at room temperature for $30 \mathrm{~min})$. Aliquots $(25 \mu \mathrm{L})$ of distilled water, standards, and unknowns (perchloric acid supernatants after centrifugation) were pipetted in 
duplicate into a 96 -well plate. Then, $200 \mu \mathrm{L}$ of working reagent [50 parts of bicinchoninic acid solution and 1 part of copper (II) sulfate pentahydrate $4 \%$ solution] were pipetted into each well. The plate was covered with film and incubated at $60^{\circ} \mathrm{C}$ for $15 \mathrm{~min}$ before reading at $562 \mathrm{~nm}$ using a plate reader.

\section{Statistical Analysis}

Daily and weekly statistical analysis was performed using the GLIMMIX, MIXED, LOGISTIC, and LIFETEST procedures of SAS (v9.4, SAS Institute Inc., Cary, NC). A linear mixed model (MIXED procedure) was constructed to analyze data for growth, feed intakes, and blood metabolites. The model contained the fixed effects of AFS (E or AF), SUP (NG or G), the interaction of AFS and SUP, time (day or week), and interactions of time with treatments. Replicate and calf were considered random effects; calf was nested within replicate, AFS, and SUP. Time (day or week) was specified as the repeated factor with calf nested within replicate, AFS, and SUP as subject. Calf was the experimental unit. The covariance structures considered for repeated measures analysis were compound symmetric, autoregressive order one, and unstructured. The covariance structure that yielded the lowest Akaike information criterion-corrected value was autoregressive order one, and therefore it was used in the models (Littell et al., 1998). Initial measurements (before treatment administration) of BW, withers height, body length, heart girth, hip height, hip width, and concentrations of plasma albumin, ASP, cortisol, haptoglobin, and $\mathrm{Zn}$ at $\mathrm{d} 0$ were used as covariates when analyzing the respective data. Least squares means were calculated and are presented with respective standard error of the mean. Degrees of freedom were estimated by using the Kenward-Roger method in the model statement (Littell et al., 1998). Residual distribution for each variable was evaluated for normality and homoscedasticity.

Daily health data were analyzed using multivariable logistic mixed models (GLIMMIX procedure) considering the count outcome variables: number of calves having high fecal score (fecal score $\geq 3$ in a 1 to 4 scale), number of days with high fecal score, percentage of calves with high fecal score, number of calves with high respiratory score (respiratory score $\geq 3$ in a 1 to 5 scale), number of days with high respiratory score, and percentage of calves with high respiratory score. The model contained the fixed effects of AFS and SUP, the interaction of AFS and SUP, time (week), and interactions of time with AFS and SUP. When the variance and means of fecal and respiratory scores were evaluated, the data were found to be over-dispersed. To compensate, negative binomial regression analysis was used to establish relationships of the fixed effects AFS, SUP, and the interaction of AFS and SUP. Means for variables are presented with their respective SEM as well as the odds ratio (OR).

Calf survival analysis was assessed using a Cox proportional hazard model (LIFETEST procedure). The fixed effects of AFS, SUP, and the interaction of AFS and SUP were treated as strata and forced into the model. The assumption of the proportionality of hazard of the model was assessed graphically by plotting the logarithm of the hazard function versus the logarithm of time. Residuals were evaluated for homogeneous distribution. Finally, a logistic regression model (LOGISTIC procedure) considering the binary outcome variable mortality was constructed. The OR from main effects and treatments are described. In all statistical procedures significant differences were declared when $P$ $\leq 0.05$, and trends toward significant effects were noted when $0.05<P \leq 0.10$.

\section{RESULTS}

\section{Ambient Temperature}

Mean low and high ambient temperatures ranged from -4.7 to $16.5,-16.0$ to 11.8 , and -10.4 to $14.1^{\circ} \mathrm{C}$ for replicates 1, 2, and 3, respectively. Ambient temperature was below the lower critical temperature of $15^{\circ} \mathrm{C}$ (NRC, 2001) most of the time throughout the study (Figure 1), indicating that calves needed to expend energy for thermoregulation.

\section{Nutrient Composition of Diets}

Analyzed nutrient composition of milk replacer and starter are listed in Table 1. Commercial milk replacer was declared to contain $20 \% \mathrm{CP}$ on an as-fed basis and the actual analyzed CP (DM basis) was $21.7 \%$. Similarly, commercial starter declared to contain $20 \%$ $\mathrm{CP}$ on an as-fed basis had measured $\mathrm{CP}$ content (DM basis) of $23.6 \%$. Chemical analysis of AF and $\mathrm{G}$ indicated that $\mathrm{CP}$ content on a DM basis was 47.5 and $75.3 \%$, respectively (Table 1). Although nutrient composition of milk replacer and starter were similar, $G$ supplementation provided greater DM and CP intake in supplemented calves.

\section{Initial Plasma Protein and Serum IgG Concentrations}

At arrival calves were blocked by plasma protein concentration determined by refractometry, which did not differ among treatments (Table 2). Initial concentrations of IgG in serum analyzed later also did not differ significantly among treatment groups (Table 2), 
Table 1. Analyzed chemical composition of milk replacer, starter grain, Gammulin (G), and Arrival Formula $(\mathrm{AF})$

\begin{tabular}{lcccc}
\hline Component & Milk replacer $^{1}$ & Starter grain $^{2}$ & $\mathrm{G}^{3}$ & $\mathrm{AF}^{4}$ \\
\hline $\mathrm{DM}, \%$ & 93.8 & 87.9 & 93.5 & 90.6 \\
$\mathrm{CP}, \%$ of DM & 21.7 & 23.6 & 75.3 & 47.5 \\
Crude fat, \% of DM & 18.9 & $\mathrm{ND}$ & 1.60 & 4.5 \\
Ash, \% of DM & 10.0 & $\mathrm{ND}$ & 6.12 & 12.3 \\
$\mathrm{Ca}, \%$ of DM & 0.74 & 1.19 & 0.87 & 0.81 \\
$\mathrm{P}, \%$ of DM & 0.72 & 0.62 & 0.26 & 0.17 \\
$\mathrm{Mg}, \%$ of DM & 0.14 & 0.29 & 0.07 & 0.10 \\
$\mathrm{~K}, \%$ of DM & 2.27 & 1.19 & 0.18 & 0.85 \\
$\mathrm{Na}, \%$ of DM & 0.99 & 0.27 & 1.11 & 2.32 \\
$\mathrm{~S}, \%$ of DM & 0.32 & $\mathrm{ND}$ & 1.11 & 0.67 \\
$\mathrm{Fe}, \mathrm{mg} / \mathrm{kg}$ & 102 & 136 & 131 & 121 \\
$\mathrm{Zn}, \mathrm{mg} / \mathrm{kg}$ & 57 & 23 & 358 & 121 \\
$\mathrm{Cu}, \mathrm{mg} / \mathrm{kg}$ & 7 & 107 & 83 & 5 \\
$\mathrm{Mn}, \mathrm{mg} / \mathrm{kg}$ & 38 & 1.4 & 160 & 57 \\
$\mathrm{Mo}, \mathrm{mg} / \mathrm{kg}$ & 0.8 & 0.8 & 0.6 \\
\hline
\end{tabular}

${ }^{1}$ Commercial nonmedicated milk replacer (Sav-A-Caf; Milk Products LLC, Chilton, WI) containing all milk proteins, $20 \% \mathrm{CP}$ and $20 \%$ fat, fed to all calves.

${ }^{2}$ Commercial starter (20\% MomentaCalf Starter - RUM; Vita Plus Corporation, Madison, WI) containing $20 \%$ $\mathrm{CP}$ provided to all calves for ad libitum intake from d 4 until $56 . \mathrm{ND}=$ not determined.

${ }^{3}$ Gammulin (APC Inc., Ankeny, IA) nutritional supplement added to reconstituted milk replacer. Supplemented twice daily by adding $25 \mathrm{~g}$ at each feeding $(50 \mathrm{~g} / \mathrm{d})$ to the reconstituted milk replacer during the first $14 \mathrm{~d}$ after arrival only.

${ }^{4}$ Arrival Formula (APC Inc.) nutritional supplement administrated via nipple feeder or esophageal feeder upon arrival. Prepared by mixing $250 \mathrm{~g}$ of $\mathrm{AF}$ in $2 \mathrm{~L}$ of warm $\left(45^{\circ} \mathrm{C}\right)$ water.

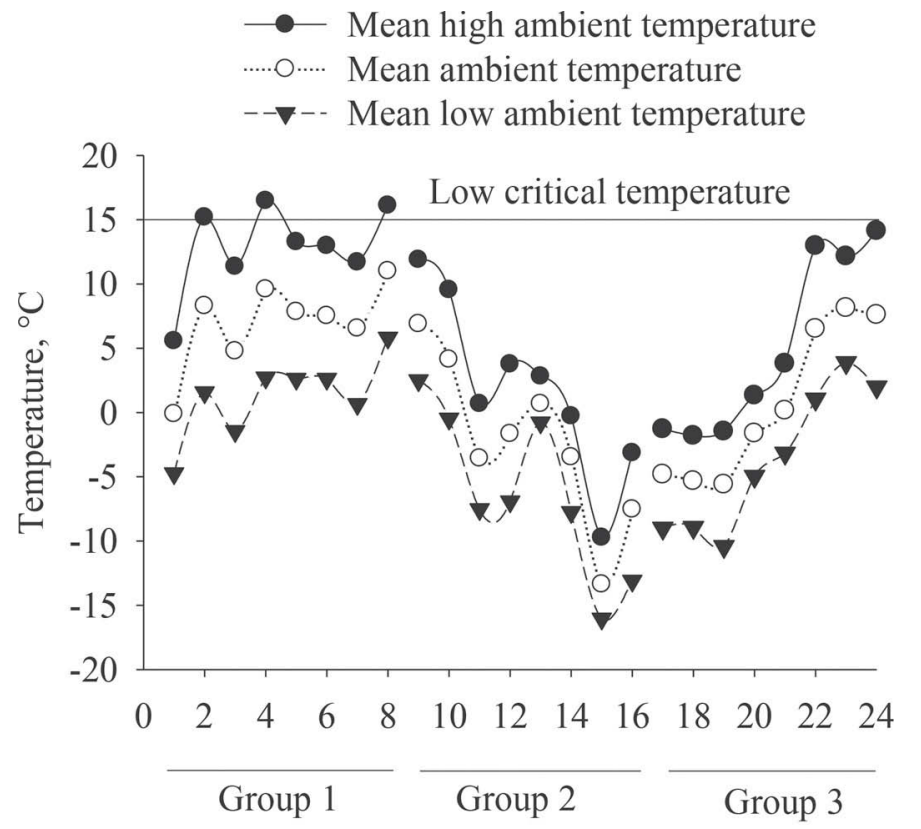

Time, wk

Figure 1. Mean high, mean, and mean low ambient temperature during research period by group of calves. The first group was acquired in February 2009 (32 calves), the second group in November 2009 (31 calves), and the third in January 2010 (30 calves). Each group remained in the study for 8 wk. Ambient temperatures were obtained from the Illinois State Water Survey (http://www.isws.illinois.edu/ atmos/statecli/cuweather/index.htm). although we noted a weak tendency $(P=0.13)$ for greater $\operatorname{IgG}$ in calves that subsequently received $\mathrm{G}$. Total plasma protein was analyzed after the experiment to further explore this relationship, but it too did not differ significantly among treatments (Table 2). The number of calves with initial IgG below $1.0 \mathrm{~g} / \mathrm{dL}$ $(10 \mathrm{~g} / \mathrm{L})$ was numerically less for calves assigned to $\mathrm{G}$ (Table 2).

\section{Intakes}

Calves were fed a limited amount of milk replacer $(10$ to $12 \%$ of arrival $\mathrm{BW}$ ) as described. Compared with NG calves, calves supplemented with $\mathrm{G}$ had $54.5 \mathrm{~g} / \mathrm{d}$ greater $(P<0.01)$ DMI from milk replacer during the supplementation period primarily because of the addition of G (Table 3). Supplementation with G resulted in $36.2 \mathrm{~g} / \mathrm{d}$ greater $(P<0.01)$ intake of milk replacer $\mathrm{CP}$ in G-supplemented calves than in NG calves (Table 3). Calf starter was offered ad libitum from d 4 to help meet nutrient requirements and support growth. Although the amount of starter intake during the first 2 wk was not large, calves fed AF had greater intakes of DM $(15.1 \mathrm{~g} / \mathrm{d})$ and CP $(3.7 \mathrm{~g} / \mathrm{d})$ from starter $(P<$ $0.01)$ and tended to have greater total DMI $(P=0.09)$ than calves fed $\mathrm{E}$. As a result of greater intakes of DM and $\mathrm{CP}$, both imposed ( $\mathrm{G}$ added to milk replacer) and voluntary (starter), calves supplemented with $\mathrm{G}$ had greater $(P<0.01)$ intakes of total $\mathrm{DM}$ and total $\mathrm{CP}$ 
Table 2. Initial plasma protein and serum IgG concentrations for calves assigned to electrolyte plus milk replacer without Gammulin (EN; APC Inc., Ankeny, IA), arrival formula plus milk replacer without Gammulin (AFN), electrolyte plus milk replacer with Gammulin (EG), or arrival formula plus milk replacer with Gammulin (AFG)

\begin{tabular}{|c|c|c|c|c|c|c|c|c|}
\hline \multirow[b]{2}{*}{ Variable } & \multicolumn{4}{|c|}{ Treatment } & \multirow[b]{2}{*}{$\mathrm{SEM}^{1}$} & \multicolumn{3}{|c|}{$P$-value ${ }^{2}$} \\
\hline & $\mathrm{EN}$ & $\mathrm{AFN}$ & EG & $\mathrm{AFG}$ & & AFS & SUP & $\mathrm{AFS} \times \mathrm{SUP}$ \\
\hline Calves per treatment & 25 & 24 & 22 & 22 & - & - & - & - \\
\hline Plasma protein,${ }^{3} \mathrm{~g} / \mathrm{dL}$ & 5.60 & 5.71 & 5.59 & 5.67 & 0.19 & 0.62 & 0.89 & 0.93 \\
\hline Plasma protein, ${ }^{4} \mathrm{~g} / \mathrm{dL}$ & 5.79 & 5.89 & 5.95 & 5.93 & 0.26 & 0.83 & 0.61 & 0.77 \\
\hline Serum $\operatorname{IgG}{ }^{5} \mathrm{~g} / \mathrm{dL}$ & 0.98 & 1.42 & 1.38 & 1.35 & 0.21 & 0.23 & 0.13 & 0.27 \\
\hline Number of calves with $\operatorname{IgG}<1.0 \mathrm{~g} / \mathrm{dL}$ & 14 & 11 & 7 & 6 & - & - & - & - \\
\hline
\end{tabular}

${ }^{1}$ Greatest SEM.

${ }^{2} \mathrm{AFS}=$ arrival fluid support; SUP = early-life dietary supplementation.

${ }^{3}$ Measured on day of arrival (d 0) by refractometry; used to stratify and block calves for treatment assignment.

${ }^{4}$ Measured at completion of the study in samples from day of arrival (d 0) with commercial kit.

${ }^{5}$ Measured at completion of the study in samples from day of arrival (d 0).

during the first $2 \mathrm{wk}$ (Table 3 ) of 50.1 and $35.1 \mathrm{~g} / \mathrm{d}$, respectively. Greater starter intake in AF-fed calves led to greater starter ME intake $(P<0.01$; Table 3$)$. Trends toward significance were observed in the interaction AFS and SUP for intakes of milk replacer DM $(P=$ $0.08), \mathrm{CP}(P=0.08)$, and ME $(P=0.09)$. As designed, supplementation of the high-CP G supplement resulted in calves fed AFG or EG having greater intakes of milk replacer DM $(P<0.01)$ and $\mathrm{CP}(P<0.01)$ compared with calves fed AFN or EN. Additionally, calves fed the EG treatment had greater $(P=0.04)$ intake of $\mathrm{ME}$ from milk replacer than calves receiving the EN treatment (Table 3).

Calves supplemented with $\mathrm{G}$ had $0.2 \mathrm{~kg} / \mathrm{d}$ lower $(P$ $=0.02$ ) free water intake than NG-supplemented calves (Table 3). We found no difference in intakes of water in milk replacer or total water; however, water intake from feed was affected by $\operatorname{AFS}(P=0.02)$ and SUP $(P<$ 0.01 ; Table 3 ). These differences were small and likely not biologically significant.

Through 8 wk, intakes were not affected by the main effects of AFS or SUP except for milk replacer DM and CP intake (Table 4). Greater mean intake $(P<$ 0.01 ) of milk replacer DM and CP through 8 wk was the result of increased intake of milk replacer DM and $\mathrm{CP}$ at 2 wk (Table 4), as designed. Through 8 wk, significant interactions of SUP and week $(P<0.01)$ were observed for milk replacer DM, milk replacer $\mathrm{CP}$, and total CP intake. Milk replacer DM and CP intakes increased from wk 1 to 2 and were greater $(P<0.01)$ for G-supplemented calves, as designed (Figure 2A, B). After the second week, intakes of G-supplemented

Table 3. Mean daily intakes of DM, CP, and ME from milk replacer and starter, and water intake from wk 1 to 2 for calves fed electrolyte plus milk replacer without Gammulin (EN), arrival formula plus milk replacer without Gammulin (AFN), electrolyte plus milk replacer with Gammulin (EG), or arrival formula plus milk replacer with Gammulin (AFG)

\begin{tabular}{|c|c|c|c|c|c|c|c|c|}
\hline Variable & \multicolumn{4}{|c|}{ Treatment $^{1}$} & $\mathrm{SEM}^{2}$ & \multicolumn{3}{|c|}{$P$-value ${ }^{3}$} \\
\hline Total DM, g/d & 544 & 580 & 609 & 615 & 19.1 & 0.09 & $<0.01$ & 0.21 \\
\hline Starter DM, g/d & 26 & 38 & 21 & 40 & 4.37 & $<0.01$ & 0.54 & 0.70 \\
\hline Total CP, g/d & 118 & 127 & 157 & 158 & 5.07 & 0.12 & $<0.01$ & 0.20 \\
\hline Milk replacer $\mathrm{CP}, \mathrm{g} / \mathrm{d}$ & 112 & 116 & 152 & 148 & 5.32 & 0.95 & $<0.01$ & 0.08 \\
\hline Starter ME, Mcal/d & 0.09 & 0.13 & 0.07 & 0.14 & 0.01 & $<0.01$ & 0.71 & 0.36 \\
\hline Total water intake, $\mathrm{kg} / \mathrm{d}$ & 4.48 & 4.74 & 4.57 & 4.43 & 0.19 & 0.54 & 0.30 & 0.05 \\
\hline Free water, kg/d & 0.59 & 0.71 & 0.49 & 0.44 & 0.18 & 0.43 & 0.02 & 0.34 \\
\hline Water in milk replacer, $\mathrm{kg} / \mathrm{d}$ & 3.85 & 3.99 & 4.04 & 3.94 & 0.13 & 0.78 & 0.32 & 0.09 \\
\hline Water in feed, ${ }^{4} \mathrm{~kg} / \mathrm{d}$ & 0.04 & 0.04 & 0.04 & 0.04 & 0.002 & 0.02 & $<0.01$ & 0.44 \\
\hline
\end{tabular}

${ }^{1}$ Gammulin (APC Inc., Ankeny, IA).

${ }^{2}$ Greatest SEM.

${ }^{3}$ Interactions of treatments with time were nonsignificant $(P>0.15)$. AFS = arrival fluid support; SUP = early-life dietary supplementation.

${ }^{4}$ Water in starter and milk replacer powder. 
Table 4. Mean daily intakes of DM, CP, and ME from milk replacer and starter, and water intake from wk 1 to 8 for calves fed electrolyte plus milk replacer without Gammulin (EN), arrival formula plus milk replacer without Gammulin (AFN), electrolyte plus milk replacer with Gammulin (EG), or arrival formula plus milk replacer with Gammulin (AFG)

\begin{tabular}{|c|c|c|c|c|c|c|c|c|}
\hline \multirow[b]{2}{*}{ Variable } & \multicolumn{4}{|c|}{ Treatment $^{1}$} & \multirow[b]{2}{*}{$\mathrm{SEM}^{2}$} & \multicolumn{3}{|c|}{$P$-value ${ }^{3}$} \\
\hline & $\mathrm{EN}$ & $\mathrm{AFN}$ & EG & $\mathrm{AFG}$ & & AFS & SUP & $\mathrm{AFS} \times \mathrm{SUP}$ \\
\hline Total DM, g/d & 1,227 & 1,220 & 1,148 & 1,219 & 53.3 & 0.47 & 0.43 & 0.42 \\
\hline Milk replacer DM, g/d & 478 & 477 & 493 & 490 & 19.4 & 0.44 & $<0.01$ & 0.87 \\
\hline Starter DM, g/d & 865 & 860 & 776 & 851 & 60.2 & 0.25 & 0.15 & 0.31 \\
\hline Total CP, g/d & 282 & 281 & 270 & 287 & 12.8 & 0.44 & 0.63 & 0.45 \\
\hline Milk replacer $\mathrm{CP}, \mathrm{g} / \mathrm{d}$ & 104 & 103 & 115 & 114 & 5.11 & 0.45 & $<0.01$ & 0.78 \\
\hline Starter CP, g/d & 204 & 203 & 184 & 201 & 15.0 & 0.25 & 0.15 & 0.32 \\
\hline Total ME, Mcal/d & 4.48 & 4.45 & 4.17 & 4.41 & 0.17 & 0.48 & 0.18 & 0.44 \\
\hline Milk replacer ME, Mcal/d & 2.02 & 2.01 & 2.02 & 2.01 & 0.08 & 0.44 & 0.73 & 0.91 \\
\hline Starter ME, Mcal/d & 2.95 & 2.93 & 2.65 & 2.90 & 0.20 & 0.25 & 0.15 & 0.31 \\
\hline Total water intake, $\mathrm{kg} / \mathrm{d}$ & 4.84 & 4.64 & 4.97 & 4.80 & 0.20 & 0.28 & 0.16 & 0.88 \\
\hline Free water, $\mathrm{kg} / \mathrm{d}$ & 2.04 & 2.16 & 1.84 & 2.00 & 0.16 & 0.13 & 0.13 & 0.88 \\
\hline Water in milk replacer, $\mathrm{kg} / \mathrm{d}$ & 3.57 & 3.55 & 3.56 & 3.55 & 0.13 & 0.43 & 0.73 & 0.91 \\
\hline Water in feed, ${ }^{4} \mathrm{~kg} / \mathrm{d}$ & 0.14 & 0.14 & 0.13 & 0.14 & 0.01 & 0.39 & 0.31 & 0.38 \\
\hline
\end{tabular}

${ }^{1}$ Gammulin (APC Inc., Ankeny, IA).

${ }^{2}$ Greatest SEM.

${ }^{3}$ Interactions of treatments with time were nonsignificant $(P>0.15)$. AFS $=$ arrival fluid support; SUP $=$ early-life dietary supplementation.

${ }^{4}$ Water in starter and milk replacer powder.

calves decreased and became similar to intakes of NGsupplemented calves because of the removal of $\mathrm{G}$ from the diet (Figure 2). Total CP intake through 2 wk was greater $(P=0.01)$ for calves supplemented with $\mathrm{G}$; from the second week, total $\mathrm{CP}$ intake was similar for G- and NG-supplemented calves (Figure 2C).

\section{Growth}

Initial calf BW (Table 5) and body conformation measures (data not presented) did not differ among treatment groups. Differences at 2 wk were not pronounced; neither AFS nor SUP had a great effect on most growth parameters at this time. Calves fed AF had greater $(P=0.05)$ body length and tended to have greater $(P=0.07)$ heart girth than calves fed $\mathrm{E}$; conversely, calves supplemented with $\mathrm{G}$ tended $(P=$ 0.06 ) to have greater $\mathrm{BW}$ than NG calves (data not presented). Through $8 \mathrm{wk}, \mathrm{BW}$ and body conformation parameters, except for hip width, were similar for all groups of calves. Calves fed AF exhibited greater $(P=$ 0.03 ) hip width (Table 5) than those fed E, but differences were numerically small. The interaction AFS and SUP was significant $(P=0.04)$ for hip height. Calves fed AFG or EN treatments had greater $(P=0.05)$ hip height than EG-fed calves (Table 5).

The SUP and week interaction was significant for withers height $(P=0.05)$ and gain-to-feed ratio $(P<$ $0.01)$, and tended to be significant for ADG $(P=0.06)$ and mean BW $(P=0.07)$. Through 8 wk, ADG did not differ among treatments, except in the first week where G-supplemented calves had superior $(P=0.03)$ ADG compared with nonsupplemented calves (Figure 3A). Feed efficiency was greater $(P<0.01)$ for G-supplemented calves in the first week only, then became lower $(P<0.05)$ until wk 4 for these same calves. After wk 5 , no differences were detected in feed efficiency between G- and NG-supplemented calves (Figure 3B).

\section{Mortality, Health, and Medical Treatments}

Mortality was greater $(P=0.02)$ for calves that did not receive $\mathrm{G}$ (Table 6, Figure 4). Analysis of plasma IgG revealed that the concentration of IgG was lower $(P$ $<0.01$ ) in calves that died than in those that survived (Figure 5). Although we found no difference in number of electrolyte administrations among treatments, calves supplemented with $\mathrm{G}$ received fewer $(P=0.05)$ antibiotic treatments than calves without $G$ supplementation (Table 6).

When data from wk 1 and 2 were analyzed separately, neither SUP nor AFS supplementation affected mean fecal score, days with high fecal score, number of calves with high fecal score, or percentage of calves with high fecal score (data not presented). However, the interaction of the main effect AFS and week was significant $(P=0.01)$ for fecal score. Mean fecal score decreased from wk 1 to 2 for calves fed AF, whereas the opposite occurred for E-fed calves. Over the 8-wk experiment, calves supplemented with $\mathrm{G}$ had lower $(P=0.01)$ mean fecal scores than NG-supplemented calves (Table 6). During the first $2 \mathrm{wk}$ after arrival, calves supplemented with $\mathrm{G}$ had lower $(P \leq 0.01)$ mean respiratory score, fewer days with high respiratory scores, fewer calves 

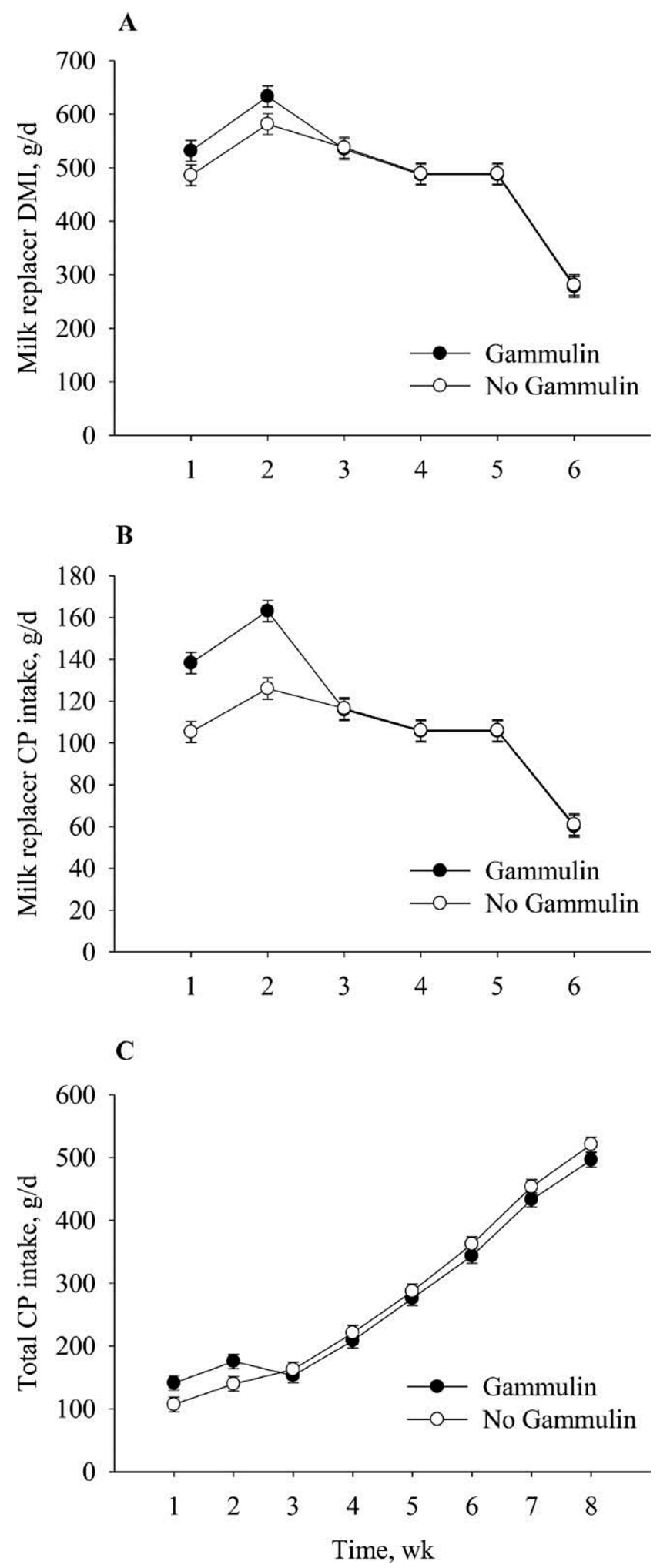

Figure 2. Least squares means and associated SEM for daily intakes of milk replacer DM, milk replacer $\mathrm{CP}$, and total $\mathrm{CP}$ for calves supplemented or not with Gammulin (APC Inc., Ankeny, IA). (A) Milk replacer DMI from wk 1 to 6 [early-life supplementation (SUP) $\times$ wk, $P<0.01$ ]; (B) milk replacer CP intake from wk 1 to $6($ SUP $\times$ wk, $P<0.01$ ); (C) total CP intake from wk 1 to 8 (SUP $\times$ wk, $P<0.01$ ). with high respiratory scores, and a smaller percentage of calves with high respiratory scores compared with NG-supplemented calves (Table 6). Over the entire $8 \mathrm{wk}$, a significant interaction of SUP and week $(P$ $=0.02$ ) was observed for respiratory score (Table 6 ). Although differences were small, calves supplemented with $\mathrm{G}$ had a lower respiratory score $(P=0.04)$ and fewer days with a high respiratory score $(P=0.01)$ than NG calves. The small difference in respiratory score in G-supplemented calves was probably due to lower respiratory score during the first 2 wk compared with NG-supplemented calves (Figure 6).

Odds ratios for effects of treatments on respiratory scores and mortality were determined (Table 7). Compared with NG-supplemented calves, G-supplemented calves had lower OR for number of calves with high respiratory scores $(\mathrm{OR}=0.32, P<0.01)$, lower $\mathrm{OR}$ for percentage of calves with high respiratory score (OR $=0.30, P<0.01)$, lower OR for the number of days with high respiratory scores $(\mathrm{OR}=0.33, P=0.01)$, and lower $\mathrm{OR}$ for mortality $(\mathrm{OR}=0.12, P=0.04)$. Calves fed treatment AFG also presented smaller OR for percentage of calves with high respiratory score $(\mathrm{OR}=0.18, P<0.01$; Table 7$)$. The main effect of AFS administration tended to result in lower OR for mortality $(\mathrm{OR}=0.80, P=0.07)$. Throughout the study, mortality occurred during the first $3 \mathrm{wk}$ (Table 7 and Figure 4).

\section{Blood Metabolites}

Although blood metabolite concentrations were statistically different $(P<0.01)$ in time, main effects and interactions of treatments with time were not significant for plasma concentrations of albumin, haptoglobin, Zn, and ASP (Table 8). Plasma cortisol, on the other hand, was higher $(P=0.04)$ for calves fed AF than for E-fed calves (17.8 vs $13.3 \mathrm{ng} / \mathrm{mL}$, respectively). Interactions of main effects and time were not significant for plasma cortisol. Urea $\mathrm{N}$ and total protein in plasma measured at wk 4 did not differ among main effects and interactions (Table 8).

\section{DISCUSSION}

The AF and G had only small effects on growth and intakes in our study, but health status, morbidity, and mortality were significantly improved. Fecal score, incidence of scours, and respiratory problems decreased during the supplementation period. Improved health in AF- and G-supplemented calves led to less antibiotic use, decreased morbidity, and less mortality. Whereas some of the differences in mortality and morbidity may have resulted from the random assignment of calves 
A

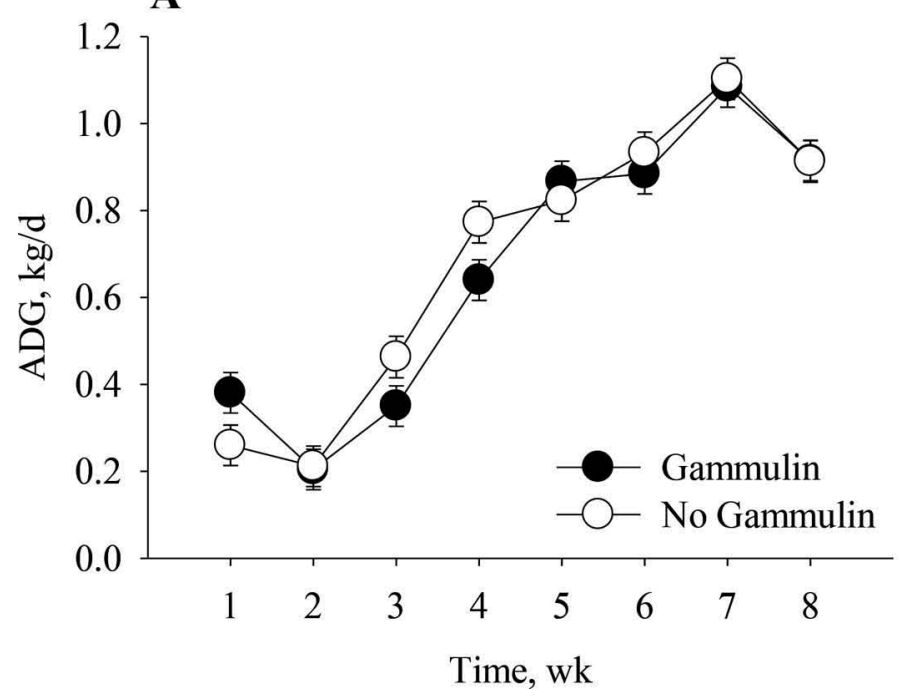

B

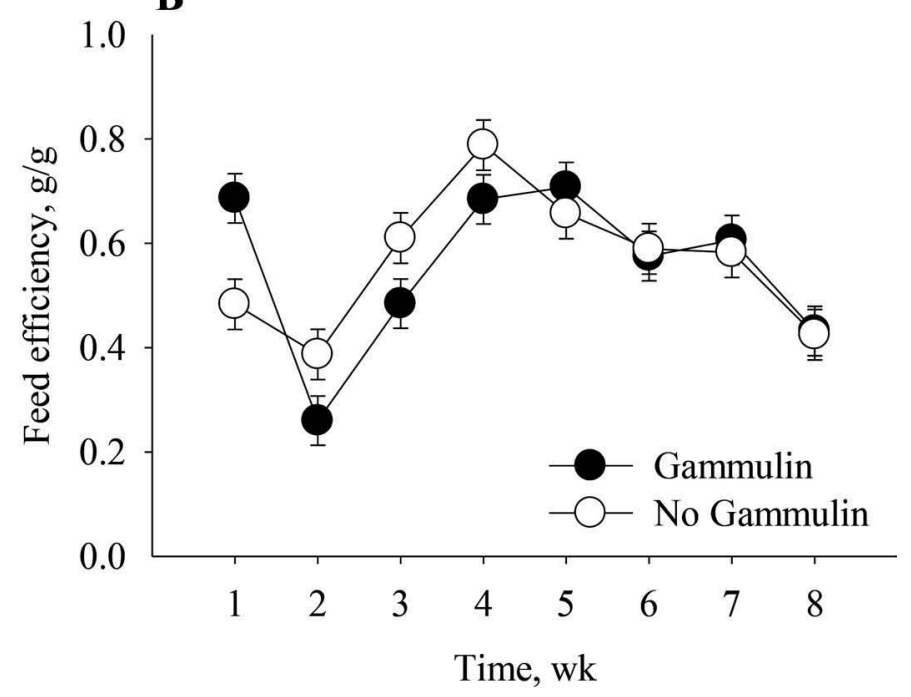

Figure 3. Least squares means and associated SEM for ADG and feed efficiency (gain:feed) from wk 1 to 8 for calves supplemented or not with Gammulin (APC Inc., Ankeny, IA). (A) Average daily gain [early-life supplementation (SUP) $\times$ wk, $P=0.06) ;(B)$ gain: feed (SUP $\times$ wk, $P<0.01)$.

with slightly better IgG status at arrival, apparent effects of G supplementation are consistent with previous research. Arthington et al. (2000a) reported fewer treatments for illness when calves were fed bovine serum as an IgG source at birth and $12 \mathrm{~h}$ later. Lower mortality and improved indices of enteric health (improved fecal scores, fewer days with diarrhea, and lower use of electrolytes) were reported by Quigley et al. (2002) when additives containing bovine serum or milk replacer containing spray-dried plasma were fed to calves. Similarly, Arthington et al. (2002) reported improvement in average respiratory rate of calves infected with coronavirus when bovine serum was supplemented. Reduced calf morbidity and mortality also were reported by Quigley and Wolfe (2003) with inclusion of spray-dried bovine or porcine plasma in milk replacer.

Serum protein-based AF contained spray-dried bovine serum, minerals, and vitamins. Gammulin contained the same components as AF plus FOS (Quigley et al., 2002). Bovine serum is a source of immunoglobulins that might provide local intestinal protection against enteric pathogens (Arthington et al., 2000a, 2002; Quigley et al., 2002; Quigley and Wolfe, 2003). Fructooligosaccharides may increase the growth and population of beneficial intestinal microorganisms, thereby improving intestinal health and decreasing incidence

Table 5. Initial, mean, and final BW; mean body conformation measurements; ADG; and feed efficiency from wk 1 to 8 for calves fed electrolyte plus milk replacer without Gammulin (EN), arrival formula plus milk replacer without Gammulin (AFN), electrolyte plus milk replacer with Gammulin (EG), or arrival formula plus milk replacer with Gammulin (AFG)

\begin{tabular}{|c|c|c|c|c|c|c|c|c|c|c|c|}
\hline \multirow[b]{2}{*}{ Variable } & \multicolumn{4}{|c|}{ Treatment $^{1}$} & \multirow[b]{2}{*}{$\mathrm{SEM}^{2}$} & \multicolumn{6}{|c|}{$P$-value ${ }^{3}$} \\
\hline & EN & AFN & EG & AFG & & AFS & SUP & $\begin{aligned} & \text { AFS } \\
\times & \text { SUP }\end{aligned}$ & $\begin{array}{c}\text { AFS } \\
\times \text { week }\end{array}$ & $\begin{array}{c}\text { SUP } \\
\times \text { week }\end{array}$ & $\begin{array}{c}\mathrm{AFS} \times \mathrm{SUP} \\
\times \text { week }\end{array}$ \\
\hline Initial BW, kg & 42.6 & 42.6 & 42.4 & 42.6 & 1.23 & 0.83 & 0.83 & 1.00 & - & - & - \\
\hline Mean BW, $\mathrm{kg}$ & 59.7 & 59.7 & 58.6 & 59.9 & 1.14 & 0.42 & 0.84 & 0.79 & 0.60 & 0.07 & 0.89 \\
\hline Final BW, $\mathrm{kg}$ & 82.1 & 80.6 & 78.8 & 80.9 & 1.86 & 0.96 & 0.38 & 0.47 & - & - & - \\
\hline Heart girth, cm & 88.6 & 89.1 & 88.2 & 88.7 & 0.45 & 0.20 & 0.30 & 0.96 & 0.70 & 0.81 & 0.07 \\
\hline Hip height, $\mathrm{cm}$ & 87.5 & 87.1 & 86.9 & 87.5 & 0.26 & 0.65 & 0.63 & 0.04 & 0.67 & 0.25 & 0.21 \\
\hline Hip width, cm & 19.2 & 19.5 & 19.1 & 19.4 & 0.13 & 0.03 & 0.31 & 0.91 & 0.43 & 0.18 & 0.13 \\
\hline $\mathrm{ADG}, \mathrm{kg} / \mathrm{d}$ & 0.69 & 0.68 & 0.65 & 0.68 & 0.03 & 0.67 & 0.55 & 0.47 & 0.61 & 0.06 & 0.81 \\
\hline Gain:feed, g/g & 0.57 & 0.56 & 0.55 & 0.55 & 0.03 & 0.76 & 0.57 & 0.78 & 0.77 & $<0.01$ & 0.99 \\
\hline
\end{tabular}

${ }^{1}$ Gammulin (APC Inc., Ankeny, IA).

${ }^{2}$ Greatest SEM.

${ }^{3} \mathrm{AFS}=$ arrival fluid support; SUP $=$ early-life dietary supplementation. 
Table 6. Mean mortality, number of electrolyte and antibiotic administrations, daily fecal score (FS) and respiratory score (RS), days with high FS and RS, number of calves with high FS and RS, and percentage of calves with high FS and RS for calves fed electrolyte plus milk replacer without Gammulin (EN), arrival formula plus milk replacer without Gammulin (AFN), electrolyte plus milk replacer with Gammulin (EG), or arrival formula plus milk replacer with Gammulin (AFG)

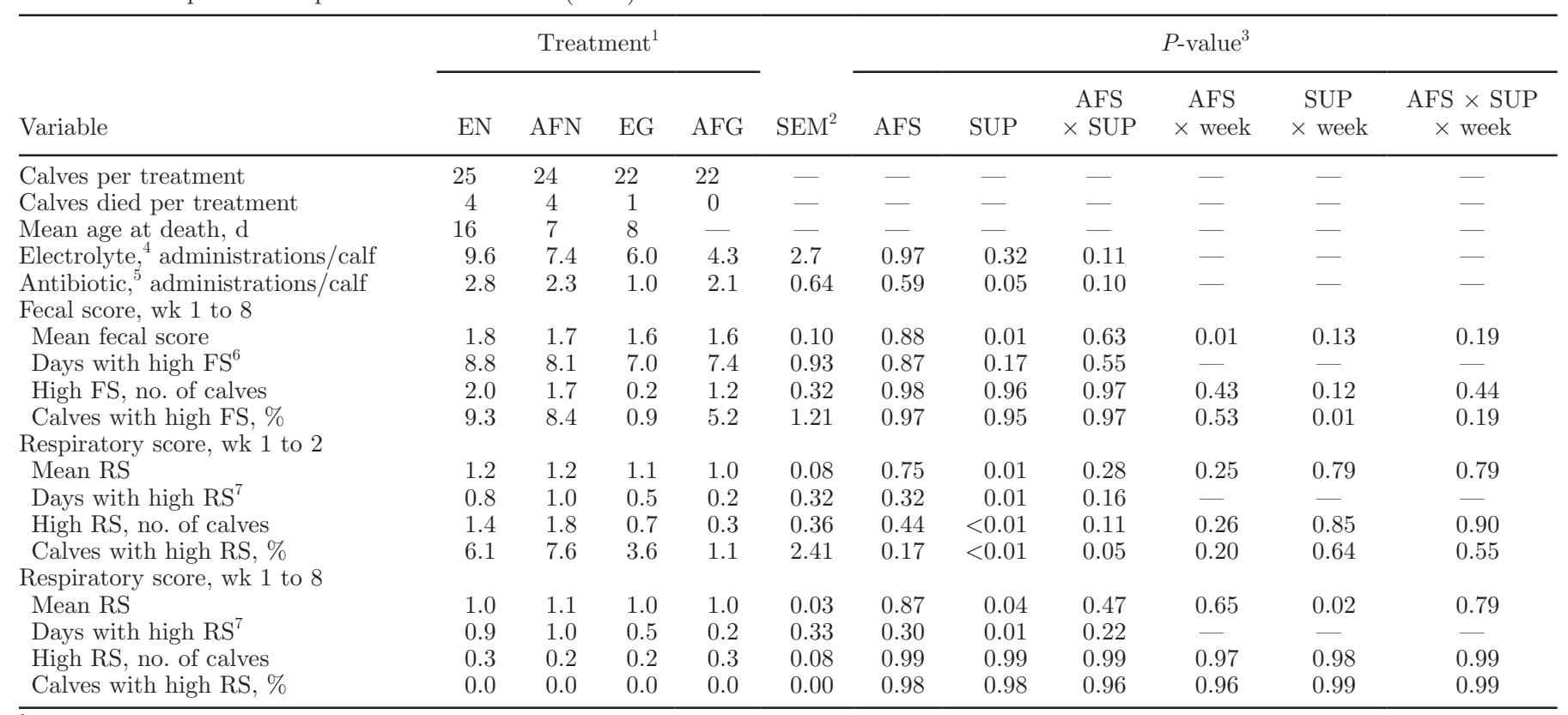

${ }^{1}$ Gammulin (APC Inc., Ankeny, IA).

${ }^{2}$ Greatest SEM.

${ }^{3} \mathrm{AFS}=$ arrival fluid support; SUP = early-life dietary supplementation.

${ }^{4}$ Electrolyte: $77 \mathrm{~g}$ of Land O'Lakes Electrolyte System solution (Land O'Lakes Animal Milk Products Co., Arden Hills, MN) mixed in 2 L of water.

${ }^{5}$ Antibiotics: individual administration of tetracycline, penicillin, ceftiofur, or tulathromycin as recommended by veterinarians blinded to treatments.

${ }^{6}$ High FS: calves with fecal score $\geq 3$ (1-4 scale).

${ }^{7}$ High RS: calves with respiratory score $\geq 3$ (1-5 scale).

or severity of diseases (Grizard and Barthomeuf, 1999; Menne et al., 2000). Because the commercial products tested in our study contained several ingredients that differed from the control treatments, it is not possible to discern whether serum proteins exerted the predominant effects or if the FOS and other ingredients worked additively or synergistically with the serum proteins. Future experiments could examine these component factors individually or in factorial combinations in comparison with appropriate controls.

Improvements in health for calves supplemented with $\mathrm{G}$ also might be related in part to greater nutrient intake in those calves, as supplementation with $\mathrm{G}$ led to greater intake of milk replacer DM and CP by design during the first $2 \mathrm{wk}$. These results agree with Quigley et al. (2002) and Quigley and Wolfe (2003), who reported, even though minimal, an increase in milk replacer intake when spray-dried serum or plasma (either from bovine or porcine origin) were fed to calves. Similar results have been described in other species; Pierce et al. (2005) reported enhanced feed intakes when spray-dried

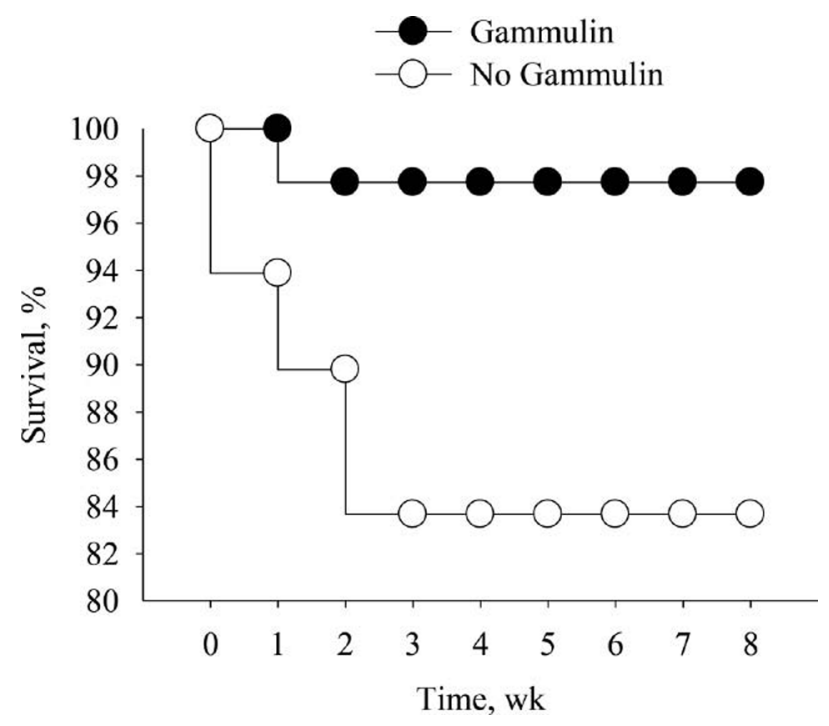

Figure 4. Survival percentage from wk 1 to 8 for calves supplemented or not with Gammulin (APC Inc., Ankeny, IA). Survival was greater for calves that received Gammulin $(P=0.02)$. Gammulin was supplemented for the first $14 \mathrm{~d}$ twice daily by adding $25 \mathrm{~g}$ at each feeding $(50 \mathrm{~g} / \mathrm{d})$ to the reconstituted milk replacer. 


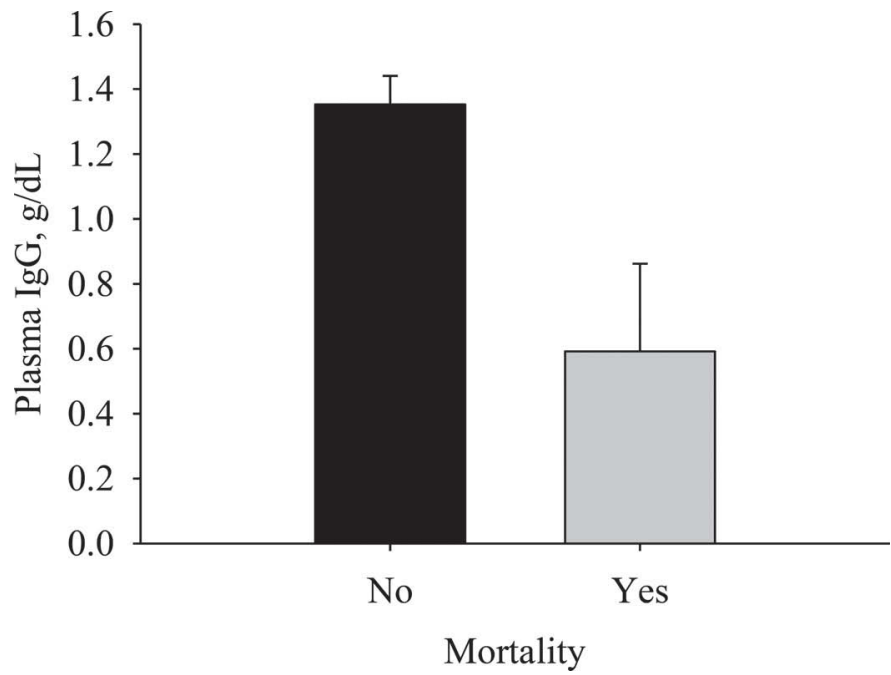

Figure 5. Least squares means and associated SEM for plasma IgG, determined by radial immunodiffusion, at arrival day before treatment assignment for calves that survived (black) or died (gray) during the 56-d experiment. Calves that died had lower initial IgG concentration $(P<0.01)$.

plasma was fed to early weaned pigs. Supplementation with serum protein and greater intakes of DM and $\mathrm{CP}$ during the first 2 wk improved BW, ADG, and feed efficiency during early serum protein supplementation. In a 56-d experiment, Quigley et al. (2002) found a $12.9 \%$ increase in BW gain from d 29 to 56 when serum protein was supplemented to calves. Morrill et al. (1995) also reported greater BW gain when calves were fed milk replacer containing plasma protein of bovine or porcine origin; however, Quigley et al. (2000) did not see a change in calf performance when spray-dried red blood cells were tested in milk replacer.

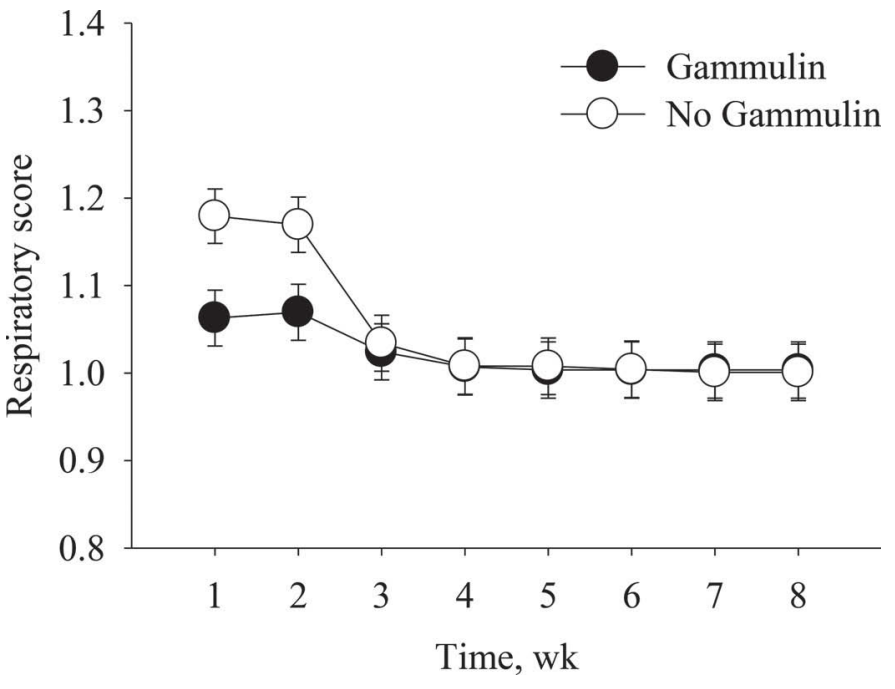

Figure 6. Least squares means and associated SEM for respiratory score from wk 1 to 8 for calves supplemented or not with Gammulin (APC Inc., Ankeny, IA; early-life supplementation $\times$ wk, $P<0.01$ ).

Although not all measures were significant, the single dose of AF given at arrival resulted in weak tendencies for greater growth during wk 1 to 2 , as shown by small increases in final BW $(P=0.17)$, heart girth $(P=$ $0.07)$, body length $(P=0.05)$, hip height $(P=0.19)$, hip width $(P=0.13)$, and ADG $(P=0.15)$. These tendencies may be related to the stimulation of starter intake during the first $2 \mathrm{wk}$. Greater early starter intake in stressed calves would be a benefit in terms of growth and resistance to disease. The improved early growth is in agreement with Jones et al. (2004), who fed a colostrum replacement derived from bovine serum at 1.5 and $13.5 \mathrm{~h}$ of age.

Table 7. Odds ratio (OR) of high respiratory score (RS) from wk 1 to 2 and mortality from wk 1 through 8 for calves fed electrolyte plus milk replacer without Gammulin (EN), arrival formula plus milk replacer without Gammulin (AFN), electrolyte plus milk replacer with Gammulin (EG), or arrival formula plus milk replacer with Gammulin (AFG) ${ }^{1}$

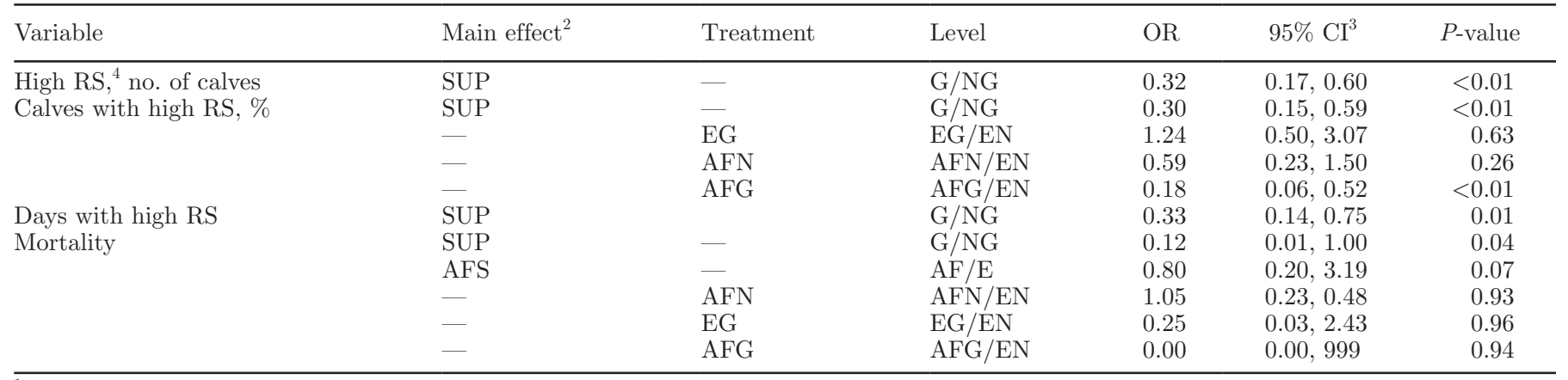

\footnotetext{
${ }^{1}$ Gammulin (APC Inc., Ankeny, IA).

${ }^{2} \mathrm{AFS}=$ arrival fluid support; SUP = early-life dietary supplementation.

${ }^{3} \mathrm{CI}$ : confidence interval derived from a negative binomial regression.

${ }^{4}$ High RS: calves with respiratory score $\geq 3$ (1-5 scale).
} 




Although concentrations of albumin, haptoglobin, $\mathrm{Zn}$, and ASP were statistically different by day, they remained within the considered normal ranges. Plasma cortisol concentrations in AF-fed calves were greater than those in calves fed $\mathrm{E}$, but concentrations were still very much lower than values of 38.0 and $79.0 \mathrm{ng} / \mathrm{mL}$ reported by Khan et al. (1970) and Willett and Erb (1972), respectively. Thus, these increases in our study were small and likely cannot be considered biologically elevated. Increases may be related to the greater protein intake during the first AFS feeding. Together, these results provide no evidence of difference in inflammation or acute phase response between calves supplemented with serum proteins and those not supplemented.

A tendency toward greater plasma protein concentrations was observed by Quigley et al. (2002) and Jones et al. (2004) when feeding milk replacer containing spray-dried bovine plasma. However, in our study, concentrations of urea $\mathrm{N}$ and total protein in plasma at wk 4 did not differ among G- and NG-supplemented calves.

\section{CONCLUSIONS}

Feeding a product containing serum proteins and FOS in addition to milk products, minerals, and vitamins to preweaned dairy calves that were exposed to stressors of transport and cold weather resulted in small differences of early feed intakes and growth but significantly decreased morbidity and mortality. The AF, which contained serum proteins in addition to additional milk solids, minerals, and vitamins, promoted starter intake, growth, and improved fecal score during the first 2 wk. Similarly, G supplementation increased early nutrient intake and stimulated early growth, decreased incidence of respiratory problems at $2 \mathrm{wk}$, and significantly decreased mortality. Whether these effects may be the result of serum proteins, FOS, and other ingredients working additively or synergistically cannot be discerned in the present study. Indicators of acutephase response were not affected by $A F$ versus $E$ or $G$ versus NG. Because serum IgG status was somewhat better by random chance in calves assigned to receive $\mathrm{G}$ than in calves that were not supplemented, decreases in mortality and morbidity in G-supplemented calves should be confirmed in studies with larger numbers of at-risk calves.

\section{ACKNOWLEDGMENTS}

The authors acknowledge partial funding of the study by APC Inc. (Ankeny, IA). The authors appreciate the donation of the electrolyte solution by Land O'Lakes Animal Milk Products Co. (Arden Hills, MN). We ex- 
tend our gratitude to all the graduate and undergraduate students that assisted with this research.

\section{REFERENCES}

Arthington, J. D., M. B. Cattell, and J. D. Quigley III. 2000a. Effect of dietary IgG source (colostrum, serum, or milk-derived supplement) on the efficiency of Ig absorption in newborn Holstein calves. J. Dairy Sci. 83:1463-1467.

Arthington, J. D., M. B. Cattell, J. D. Quigley III, G. C. McCoy, and W. L. Hurley. 2000b. Passive immunoglobin transfer in newborn calves fed colostrum or spray-dried serum protein alone or as a supplement to colostrum of varying quality. J. Dairy Sci. 83:2834-2838.

Arthington, J. D., C. A. Jaynes, H. D. Tyler, S. Kapil, and J. D. Quigley III. 2002. The use of bovine serum protein as an oral support therapy following coronavirus challenge in calves. J. Dairy Sci. 85:1249-1254.

Ballou, M. A., C. J. Cobb, L. E. Hulbert, and J. A. Carroll. 2011. Effects of intravenous Escherichia coli dose on the pathophysiological response of colostrum-fed Jersey calves. Vet. Immunol. Immunopathol. 141:76-83.

Davis, C. L., and J. K. Drackley. 1998. The Development, Nutrition, and Management of the Young Calf. Iowa State University Press, Ames, Iowa.

Fike, K., and M. F. Spire. 2006. Transportation of cattle. Vet. Clin. North Am. Food Anim. Pract. 22:305-320.

Godden, S. 2008. Colostrum management for dairy calves. Vet. Clin. North Am. Food Anim. Pract. 24:19-39.

Grand, E., F. Respondek, C. Martineau, J. Detilleux, and G. Bertrand. 2013. Effects of short-chain fructooligosaccharides on growth performance of preruminant veal calves. J. Dairy Sci. 96:1094-1101.

Grizard, D., and C. Barthomeuf. 1999. Non-digestible oligosaccharides used as prebiotic agents: Mode of production and beneficial effects on animal and human health. Reprod. Nutr. Dev. 39:563-588.

Gulliksen, S. M., K. I. Lie, T. Løken, and O. Østerås. 2009. Calf mortality in Norwegian dairy herds. J. Dairy Sci. 92:2782-2795.

Howard, M. D., D. T. Gordon, L. W. Pace, K. A. Garleb, and M. S. Kerley. 1995. Effects of dietary supplementation with fructooligosaccharides on colonic microbiota populations and epithelial cell proliferation in neonatal pigs. J. Pediatr. Gastroenterol. Nutr. 21:297-303.

Johnston, J. D., and R. B. Buckland. 1976. Response of male holstein calves from seven sires to four management stresses as measured by plasma corticoid levels. Can. J. Anim. Sci. 56:727-732.

Jones, C. M., R. E. James, J. D. Quigley III, and M. L. McGilliard. 2004. Influence of pooled colostrum or colostrum replacement on $\mathrm{IgG}$ and evaluation of animal plasma in milk replacer. J. Dairy Sci. 87:1806-1814.

Khan, M. A., W. M. Dickson, and K. M. Meyers. 1970. The effect of low environmental temperature on plasma corticosteroid and glucose concentrations in the newborn calf. J. Endocrinol. 48:355-363.

Littell, R. C., P. R. Henry, and C. B. Ammerman. 1998. Statistical analysis of repeated measures data using SAS procedures. J. Anim. Sci. 76:1216-1231.

Makimura, S., and N. Suzuki. 1982. Quantitative determination of bovine serum haptoglobin and its elevation in some inflammatory diseases. Nihon Juigaku Zasshi 44:15-21.
Menne, E., N. Guggenbuhl, and M. Roberfroid. 2000. Fn-type chicory inulin hydrolysate has a prebiotic effect in humans. J. Nutr. 130:1197-1199.

Morrill, J. L., J. M. Morrill, A. M. Feyerherm, and J. F. Laster. 1995. Plasma proteins and a probiotic as ingredients in milk replacer. J. Dairy Sci. 78:902-907.

NAHMS (National Animal Health Monitoring System). 2010. Dairy 2007 Biosecurity practices on U.S. dairy operations, 1991-2007. USDA-Animal and Plant Health Inspection Service Veterinary Services, Ft. Collins, CO.

NRC. 2001. Nutrient Requirements of Dairy Cattle. 7th rev. ed. Natl. Acad. Sci., Washington, DC.

Odore, R., A. D'Angelo, P. Badino, C. Bellino, S. Pagliasso, and G. Re. 2004. Road transportation affects blood hormone levels and lymphocyte glucocorticoid and beta-adrenergic receptor concentrations in calves. Vet. J. 168:297-303.

Pierce, J. L., G. L. Cromwell, M. D. Lindemann, L. E. Russell, and E. M. Weaver. 2005. Effects of spray-dried animal plasma and immunoglobulins on performance of early weaned pigs. J. Anim. Sci. 83:2876-2885.

Quigley, J. D., C. J. Hammer, L. E. Russell, and J. Polo. 2005. Passive immunity in newborn calves. Pages $135-157$ in Calf and Heifer Rearing. 1st ed. P. C. Garnsworthy ed. Nottingham University Press, Nottingham.

Quigley, J. D., III, C. A. Jaynes, M. L. Miller, E. Schanus, H. ChesterJones, G. D. Marx, and D. M. Allen. 2000. Effects of hydrolyzed spray dried red blood cells in milk replacer on calf intake, body weight gain, and efficiency. J. Dairy Sci. 83:788-794.

Quigley, J. D., III, C. J. Kost, and T. A. Wolfe. 2002. Effects of spraydried animal plasma in milk replacers or additives containing serum and oligosaccharides on growth and health of calves. J. Dairy Sci. 85:413-421.

Quigley, J. D., III, K. R. Martin, D. A. Bemis, L. N. Potgieter, C. R. Reinemeyer, B. W. Rohrbach, H. H. Dowlen, and K. C. Lamar. 1995. Effects of housing and colostrum feeding on serum immunoglobulins, growth, and fecal scores of Jersey calves. J. Dairy Sci. 78:893-901.

Quigley, J. D., III, and T. M. Wolfe. 2003. Effects of spray-dried animal plasma in calf milk replacer on health and growth of dairy calves. J. Dairy Sci. 86:586-592.

Sabater-Molina, M., E. Larque, F. Torrella, and S. Zamora. 2009. Dietary fructooligosaccharides and potential benefits on health. J. Physiol. Biochem. 65:315-328.

Svensson, C., J. Hultgren, and P. A. Oltenacu. 2006a. Morbidity in 3-7-month-old dairy calves in south-western Sweden, and risk factors for diarrhoea and respiratory disease. Prev. Vet. Med. 74:162179.

Svensson, C., A. Linder, and S. O. Olsson. 2006b. Mortality in Swedish dairy calves and replacement heifers. J. Dairy Sci. 89:4769-4777.

Vasseur, E., F. Borderas, R. I. Cue, D. Lefebvre, D. Pellerin, J. Rushen, K. M. Wade, and A. M. de Passille. 2010. A survey of dairy calf management practices in Canada that affect animal welfare. J. Dairy Sci. 93:1307-1315.

Wells, S. J., D. A. Dargatz, and S. L. Ott. 1996. Factors associated with mortality to 21 days of life in dairy heifers in the United States. Prev. Vet. Med. 29:9-19.

Willett, L. B., and R. E. Erb. 1972. Short term changes in plasma corticoids in dairy cattle. J. Anim. Sci. 34:103-111. 